\title{
Private clinics continue explosive growth
}

$\mathrm{W}$ hile skirmishers in the ongoing battle between private and public health care in Canada continue to slug it out through court cases, regulatory complaints and debates, the swelling number of private clinics indicates that what once was privatization trickle may soon become a wave.

"What's been tough is that it's being done underhandedly," says Cory Verbauwhede, a lawyer for Médecins Québécois pour le Régime Public, a pro-medicare group in Quebec. "No one is saying we're privatizing the system, it's being done bit by bit."

No medical association or government body keeps official track of private clinics at a national level but what evidence exists suggests that the numbers have swollen well into the hundreds. In Quebec alone, there's been a big explosion of private clinics, says Dr. Zoltan Nagy, president of the Canadian Independent Medical Clinics Association, a lobby organization for private health care in Canada. The Quebec government does not keep a comprehensive list of private clinics operating in the province but Nagy estimates there are around 300 private clinics there, including several that focus on providing executive health and cosmetic services.

Verbauwhede notes that Quebec clinics are not only expanding in number, but also in size. "They're becoming mini-hospitals," he says, noting that one-day cataract, knee and hip surgeries are increasingly being performed in private clinics.

Meanwhile, the colleges of physicians and surgeons for British Columbia and Alberta publish lists of independent clinics providing surgeries outside of hospitals, but other provincial colleges don't do so because they don't regulate such facilities (although Ontario is in the process of registering clinics that provide anesthesia).

British Columbia lists 66 clinics, many of which do only one type of surgery and about a dozen of which provide a variety of services. Alberta lists

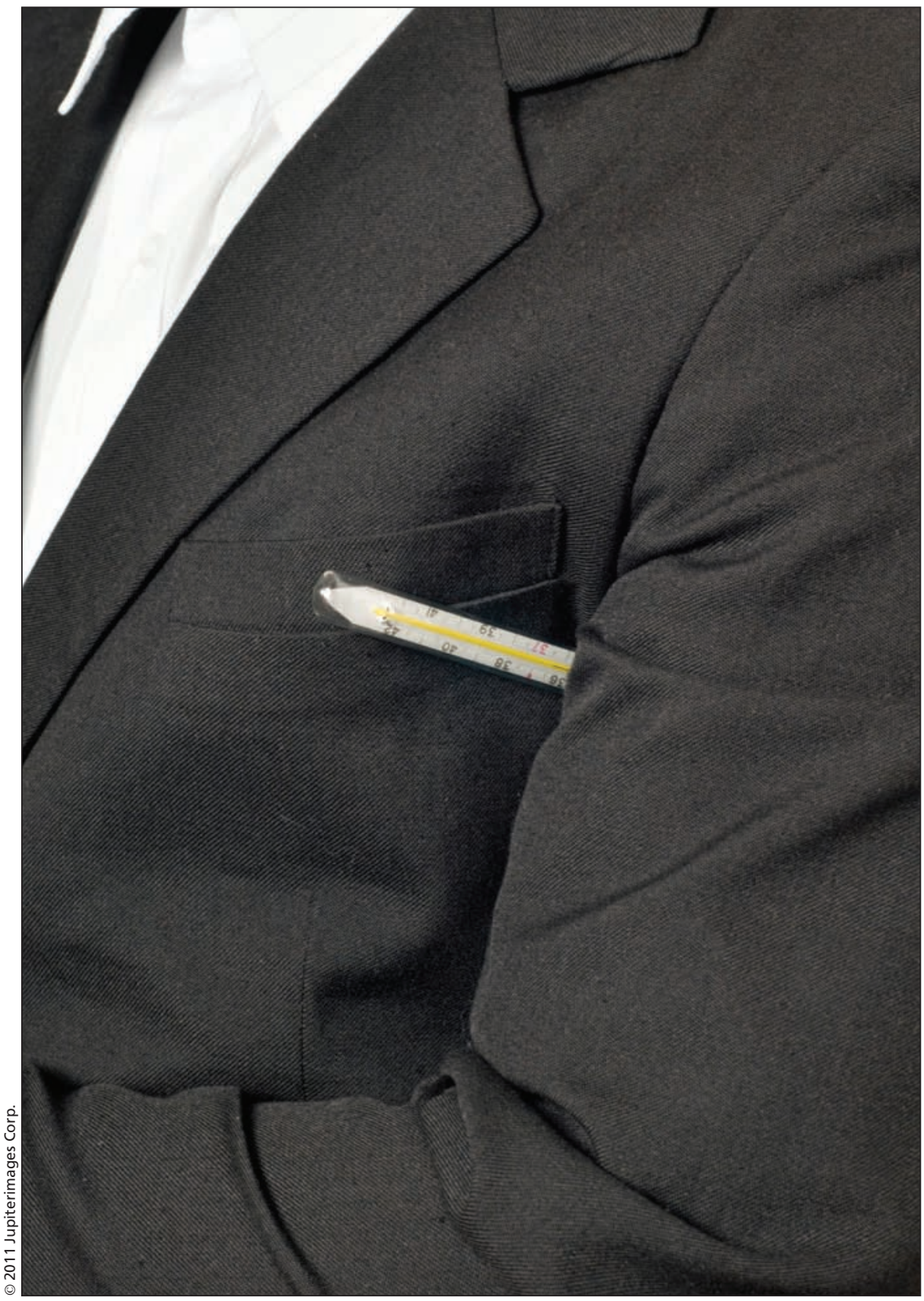

Private clinics that provide medical services for business executives have been among those that have experienced considerable growth.

60 in total, including 12 that perform multiple types of surgery. Neither the British Columbia nor Alberta numbers include private executive health or imaging clinics.

There are also indications that the growth in private clinics may soon escalate.
Perhaps the primary constraint against the growth of private clinics in Canada through the years has been a prohibition against physicians billing medicare systems while simultaneously providing services, and charging patients, for medically necessary services provided at a private clinic. 
It's a regulation that has frequently been broken across Canada, says Michael McBain, director of the Canadian Health Coalition, citing a 2008 report from the Ontario Health Coalition that indicated that roughly 90 private clinics were openly violating the prohibition by charging both patients and the government for medically necessary services (www.web.net/ ohc/Eroding\%20 Public\%20Medicare.pdf).

In Quebec, that prohibition has meant that many doctors stay in the public system because they can't get enough work in the private system to fully support themselves, Verbauwhede says.

But specialists in Quebec have launched a lawsuit in hopes of striking down the one-or-the-other rule.

"The law forbidding publicly funded doctors from working in the same setting as a nonparticipating doctor impedes on the right of people to associate themselves," says Dr. Gaétan Barette, president of Quebec's medical specialists' federation.

Verbauwhede worries that if the suit is successful for the specialists, hospitals will have a difficult time staffing full-time anesthesiologists and the like who would moonlight in private clinics.

It's an effect that often ensues from growth in private clinics, says Dr. Margaret McGregor, a family physician and health services researcher at the University of British Columbia. She argues that government payments and migration of health workers to private clinics erode the resources available to the public system. But there's often little in the way of a public outcry because most people suffer from "the misunderstanding that if this person goes to the private clinic, then I can have a shorter wait list," she adds.

Verbauwhede says that in Quebec, the movement of physicians to private clinics is already lengthening wait times in the public system. "People who don't want to pay out of pocket for an MRI [magnetic resonance imaging] will have to wait several months for an appointment."

What's driving all that growth in private clinics?

Dr. Brian Day, the owner of private Cambie Surgery Centre and former president of the Canadian Medical Association says the proliferation is a function of the inability of the public system to meet demand.

Echoing an oft-stated belief that twotier health care works well in the United Kingdom and Australia, Day says that "out of every developed country on earth, Canada is the only one where the government is trying to deliver all the health services. ... Some competition is good for the public system."

Other advocates of private clinics argue that their explosive growth is a function of innovative capacity. Private clinics provide an opportunity to try out new delivery models and technologies, says Francine Bertrand-Venne, manager of corporate affairs at Ville Marie Medical and Women's Health Center in Montréal, Quebec. "Can't we open the window to consider complementary tools?"

"Sometimes the hospital or government can't afford the technology that the patient needs," she adds, noting her clinic was the first in Canada to provide full field digital mammography.

Verbauwhede counters that better technology in the private sector "has nothing to do with innovation in the private sector - it is the consequence of huge funding cuts" in the public sector.

The government's failure to enforce the Canada Health Act is also leading to the uptick in private clinics, he adds, noting that several clinics in Montréalwere openly charging patients and billing the public system for years before an investigation was launched by the government in January.

Another area that's seen considerable growth is executive health services, which offer many of the same services as primary care clinics, Mehra notes.

Some operators say the growth in private clinics is driven by the nature of the care they offer. Patients come to private clinics for more comprehensive care, says Dr. Sanjeev Sharma, CEO of Wellpoint Health Services. "We focus on 'well care' not just 'sick care,", he says, adding that private primary care clinics are more focused on preventive care and "optimizing energy" through diet and lifestyle advice.

Wellpoint predominantly sells executive health packages to companies, which can range from $\$ 200$ to $\$ 2500$ per client, and demand is exploding, Sharma says. "Canadian companies are catching on. There's cost to 'presenteeism' where the employees are showing up for work, but they're less productive because of poor health."

But Dr. Danielle Martin, chair of Canadian Doctors for Medicare, contests that not only are executive health clinics extremely overpriced, they're also risky. Research by her organization shows the clinics are charging three times as much as what a similar check-up would cost in the public system - a fact that challenges the assertion of pro-private health care lobbies that private health care is more efficient and cheaper than public health care. And many of the additional tests offered by executive clinics can pose added risks, such as greater exposure to radiation as a result of extra diagnostic imaging, Martin argues. "We have to get the message across that more health care is not necessarily better."

While private health providers argue that patients are demanding private health care and triggering the growth, those who oppose two-tier systems say patients are feeling increasingly coerced into paying out of pocket for services caused by underfunding in the public system.

"Provinces are delisting services. The medicare blanket is shrinking," says McBain. "The government is letting us down." — Wendy Glauser, Toronto, Ont.

CMAJ 2011. DOI:10.1503/cmaj.109-3816 